Review Article

\title{
Hydrogels for the Application of Articular Cartilage Tissue Engineering: A Review of Hydrogels
}

\author{
Er-Yuan Chuang $\mathbb{D}^{1}{ }^{1}$ Chih-Wei Chiang, ${ }^{2,3}$ Pei-Chun Wong, ${ }^{2}$ and Chih-Hwa Chen $\mathbb{D}^{2}$ \\ ${ }^{1}$ Graduate Institute of Biomedical Materials and Tissue Engineering, International Ph.D. Program in Biomedical Engineering, \\ College of Biomedical Engineering, Taipei Medical University, Taipei, Taiwan \\ ${ }^{2}$ Department of Orthopedics, Taipei Medical University Hospital, Shuang Ho Hospital, School of Medicine, College of Medicine, \\ School of Biomedical Engineering, College of Biomedical Engineering, Taipei Medical University, Taipei, Taiwan \\ ${ }^{3}$ Graduate Institute of Biomedical Electronics and Bioinformatics, National Taiwan University, Taipei, Taiwan
}

Correspondence should be addressed to Chih-Hwa Chen; afachen@doctor.com

Received 27 June 2017; Revised 19 December 2017; Accepted 25 December 2017; Published 3 April 2018

Academic Editor: Jun Liu

Copyright (c) 2018 Er-Yuan Chuang et al. This is an open access article distributed under the Creative Commons Attribution License, which permits unrestricted use, distribution, and reproduction in any medium, provided the original work is properly cited.

\begin{abstract}
The treatment of articular cartilage damage is a major task in the medical science of orthopedics. Hydrogels possess the ability to form multifunctional cartilage grafts since they possess polymeric swellability upon immersion in an aqueous phase. Polymeric hydrogels are capable of physiological swelling and greasing, and they possess the mechanical behavior required for use as articular cartilage substitutes. The chondrogenic phenotype of these materials may be enhanced by embedding living cells. Artificial hydrogels fabricated from biologically derived and synthesized polymeric materials are also used as tissue-engineering scaffolds; with their controlled degradation profiles, the release of stimulatory growth factors can be achieved. In order to make use of these hydrogels, cartilage implants were formulated in the laboratory to demonstrate the bionic mechanical behaviors of physiological cartilage. This paper discusses developments concerning the use of polymeric hydrogels for substituting injured cartilage tissue and assisting tissue growth. These gels are designed with consideration of their polymeric classification, mechanical strength, manner of biodegradation, limitations of the payload, cellular interaction, amount of cells in the 3D hydrogel, sustained release for the model drug, and the different approaches for incorporation into adjacent organs. This article also summarizes the different advantages, disadvantages, and the future prospects of hydrogels.
\end{abstract}

\section{Introduction}

1.1. Introduction to Articular Cartilage. Articular cartilage is a thin layer that covers joint surfaces. In a young and normal joint, the articular cartilage is called hyaline articular cartilage, a dense, translucent, and white connective tissue. Articular cartilage is a specialized tissue that can offer shock and impact absorption, which serves to further protect bone tissue $[1,2]$.

Chondrocytes are cells that are distributed in articular cartilage, and they account for less than $10 \%$ of the volume of the tissue [3]. Even though chondrocytes are distributed in the articular cartilage, they are responsible for production, secretion, organization, and maintenance of the organic component of the extracellular matrix (ECM) [3-5]. In the body, the most abundant protein is collagen [6, 7]. Collagen accounts for a large amount of the fibrous ultrastructure in articular cartilage [8-10]. The fibrils that polymerize via rodlike tropo-collagen molecular structure $(1.4 \mathrm{~mm}$ in diameter and $300 \mathrm{~nm}$ in length) $[6,7]$ have a mean diameter around 25 to $40 \mathrm{~nm}$. Type II collagen is the main component of cartilage, and it is present in articular cartilage, sternal cartilage, and the meniscus. From a physiological viewpoint, articular cartilage is an isolated organ with no lymphatic channels, blood vessels, and neurologic innervation, and its density of cell is below that of other tissues [11].

The principal purpose of articular cartilage is for offering a lubricated, smooth surface, decreasing the frictional coefficient and stresses sustained by the contacting joint surface, and facilitating the transmission of loadings 


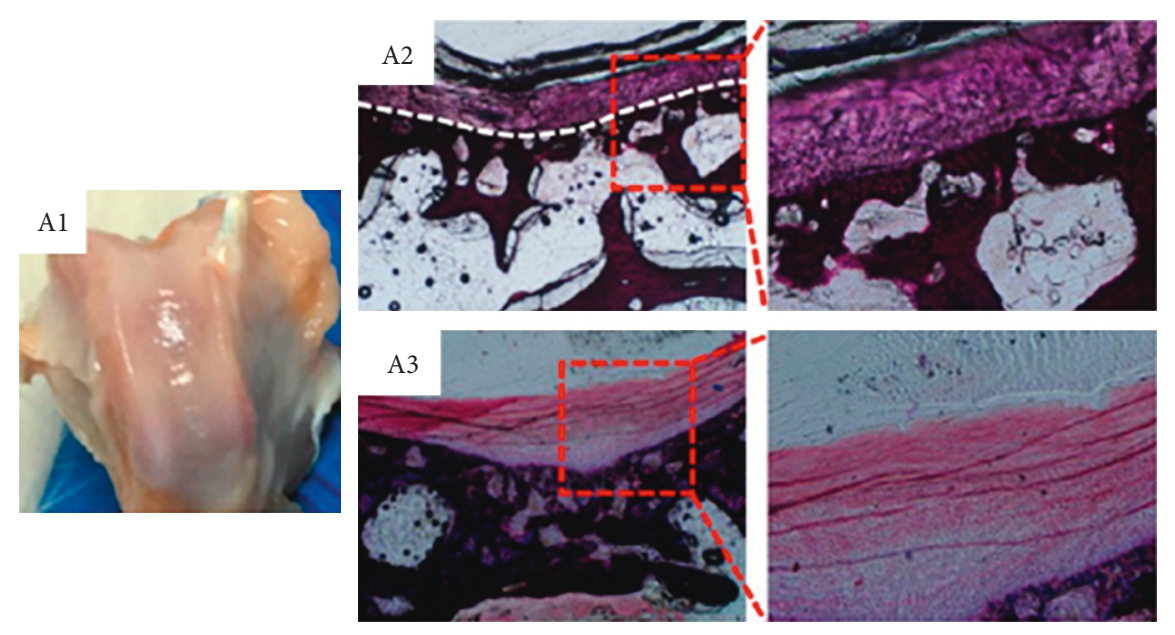

(a)

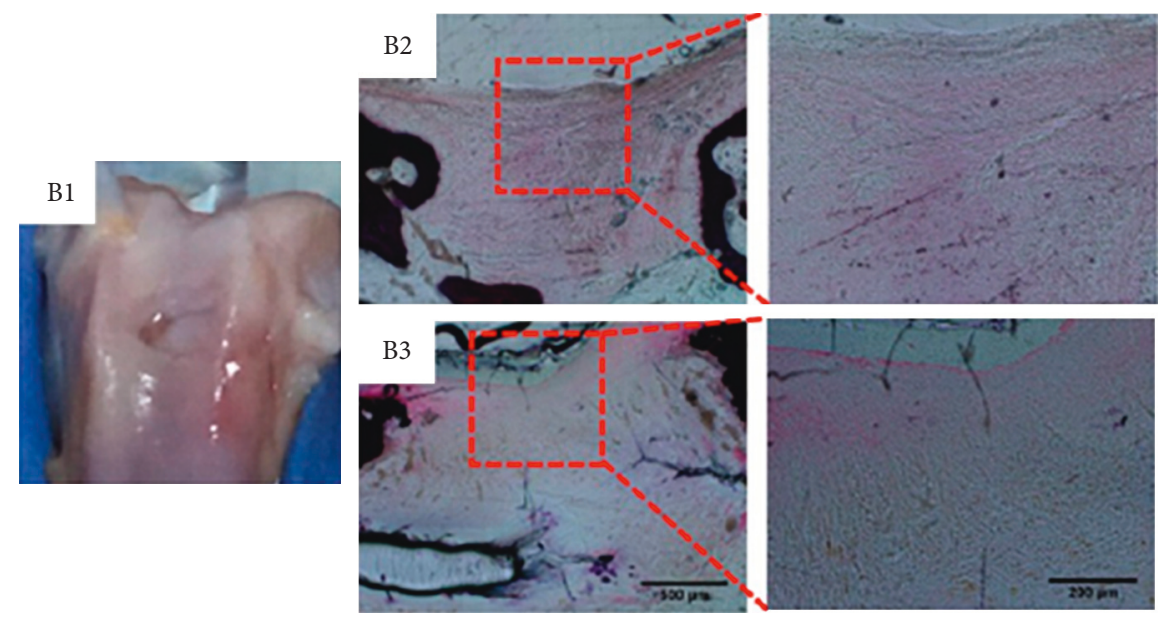

(b)

FIgURE 1: Histological examination in a rabbit articular cartilage study. Adapted with permission from [15], copyright 2017 ACS Publications.

to the underlying subchondral bone as indicated in Figure 1 [12-14].

1.2. Articular Cartilage Damage. Lesions of the articular cartilage may restrain joint function by preventing the lesion from healing spontaneously, and it may further lead to osteoarthritis (OA) [16, 17]. Articular cartilage lesions can be briefly classified into four types: (1) localized focal osteochondral or chondral lesion, (2) OA, (3) osteochondritis dissecans, and (4) other types [18]. The medial femoral condyle and patellar articular surface are locations where cartilage lesions often occur because of their presence in a weight-bearing area. Cartilage lesions can be systematically classified through the Outerbridge method [19]. This system divides cartilage lesions into four grades: Grade I is cartilage with swelling and unstiffening. Grade II is particle thickness damage with a crack on the surface where the defects do not stretch the bone located at the subchondral region or surpass $15 \mathrm{~mm}$ in diameter. Grade III is slitting of the layer of bone located at the subchondral region exceeding $15 \mathrm{~mm}$. Grade IV is bare subchondral bone
[20]. However, this classification system seems more suitable for the classification of OA rather than for cartilage injury classification [21]. Additionally, other different classification methods have been developed, such as magnetic resonance imaging evaluation [22-28] and the ICRS hyaline cartilage lesion classification system [29].

\subsection{Different Treatments for Articular Cartilage Damage} (Healing Methods). Articular cartilage injury does not heal instantly, unfortunately, and the methods for articular cartilage repair are few. Slight cartilage damage can be treated by strengthening the surrounding muscles by physiotherapy, and pain and swelling can be reduced by anti-inflammatory drugs [30-32]. However, if the cartilage injury is more serious, surgical treatment may be considered. From the point of view of pain reduction, arthroscopic lavage/debridement can be used to wash the cartilage by an injection of saline solution $[33,34]$.

Microfracture is one regeneration technique. The hematoma that contains mesenchymal stem cells (MSCs) are 
formed by small fractures created on the bone. These MSCs can differentiate into chondrocytes and create new cartilage $[35,36]$. Although this method is relatively fast, the hematoma cannot totally fill the defect [37]. Furthermore, the cartilage formed by the microfracture method is fibrocartilage; this fibrocartilage is weaker, denser, and possesses lower stiffness in comparison with hyaline cartilage [38]; these weaknesses lead to an increase in the probability of recurring damage $[39,40]$.

A second method, osteochondral autograft transplantation (mosaicplasty), involves the transfer of cartilage and subchondral bone from a nonload-bearing site to the damaged load-bearing site. Unfortunately, this method is only applicable to a small defect because of the small amount of possible donor sites [41-43]. The donor cartilage that is transplanted from a nonload-bearing site to the load-bearing site is more susceptible to damage because of the structural difference between the two regions of cartilages. To overcome this problem, osteochondral allograft transplantation is used. Cartilage from a donor cadaver may, however, pose a risk to the immune system of the recipient.

A third method is autologous chondrocyte implantation technique. This technique uses chondrocytes that have been harvested from healthy and nonweight-bearing cartilage. The cartilage is introduced into the damaged site or inserted into the scaffold of the damaged site before cells are introduced by matrix-induced autologous chondrocyte implantation $[44,45]$. This autograft method can reduce the risk of rejection and can supply cells continuously. Nevertheless, this method is very slow, and the patient must undergo multiple surgeries.

The fourth method involves total joint replacement. This method is used only for cartilage that has been damaged beyond repair. In recent years, the survival rate of total knee replacements is between $90 \%$ and $95 \%$ [46, 47]. An artificial joint has a certain period of use; thus, young patients may require more surgery for further replacements during their lifetime, resulting in increased medical expenses.

Tissue engineering is a novel method that has great potential use in cartilage repair. Cell, scaffold, and signal are the three elements of tissue engineering. In this context, the general method for cartilage tissue engineering is placing the cells and/or growth factor (signal) into the hydrogel (scaffold) in order to repair the damaged cartilage. However, cartilage that has been repaired using the tissue-engineering method does not possess sufficient mechanical properties that confer load-bearing capability [48].

Once the cartilage damage has interacted with the underlying bone marrow, a case in which there is a full-thickness crack, self-healing repair may be achievable; however, the subsequent tissues undergo fibrosis and are physically or automatically disadvantaged in the injured cartilage of patients; finally, deterioration results from overloading of the knees [49]. The microfractural subchondral method, the transplantation of cartilage plugs, and the living chondrocyte seeding method are used as surgical procedures focusing on trying to induce the self-healing repair process [17, 50-52]. On the other hand, biomaterials that are used act as artificial cartilage substitutes and encourage the renewal of newborn tissue are designed for addressing the shortcomings of other presently applied procedures [53-56]. The cartilage tissues are composed of a long chain polymeric substance such as typical collagen and glycosaminoglycan, which swells in an excess of aqueous phase and thus results in behavior similar to that of hydrogels. This also creates a three-dimensional (3D) water-soluble polymeric network that has the ability to swell to an extreme extent in an aqueous phase $[57,58]$. Since investigations on biological applications of methacrylate-based hydrogel about 60 years ago, hydrogels have been used as drug carrier systems, chemically modified implants for biomedical uses, devices used for diagnostic purposes, and for various purposes in engineered tissue [59]. Hydrogels possess biocompatibility, although many factors influence the response of the immune system to hydrogels. Some of these factors are the type of polymer, the choice of crosslinking approaches, the manner of biodegradation of the material, and the products that exist after degradation through an enzymatic process, as well as the cellular interactions involved and the behavior of the released active substance aspects [60]. The usage of hydrogels as biomaterials can be enhanced through the use of diverse factors such as the polymeric ingredients, crosslinker concentration, morphological change of the polymeric filaments, and the profile of degradation using the bioenzyme $[57,58,60]$.

For the purpose of articular cartilage substitution, the hydrogels are created to be either resident substitutes for the replacement of injured cartilage or to be constituents loaded into cell that encourage or stimulate the regeneration of new tissue. Hydrogels can automatically form cartilage tissues that have physically comparable qualities, and they permit the effective loading for transfer as cellular empty grafts [61, 62]. Hydrogels possess other valuable qualities, for instance, their ability to enhance the stimulation of chondrocyte adhesion, which affects the ECM of cartilage such that a bioscaffold exists where the cellular seeding can be considered for tissue engineering [63]. These substances also possess the ability to preserve the behavior of a chondrocyte phenotype in difficult cultures, which appear in the given cellular structure [6466]. They are also viscoelastic, allowing the transfer of support to the chondrocyte according to the mechanical requirements for survival $[67,68]$.

Numerous development variables can be adjusted to modify the properties of the hydrogels used as a substitute for cartilage or scaffold for tissue engineering. The major factors that need to be adjusted are the polymeric classification, crosslinking condition or method, manner of biodegradation and limitation of the payload, cellular interaction, amount of cells in the 3D hydrogel, sustained release time for the model drug, and approaches for inducing incorporation into adjacent organs. In the use of functional hydrogel for treating articular cartilage damage, suitable manufacture approaches and superb bio-materials act as important parts in developing perfect injectable polymeric hydrogels which could be considered as bio-scaffolds for bone and articular cartilage tissue engineering uses. A choice of biomedical materials, either synthetic or natural, has been elucidated to fabricate injectable polymeric hydrogels; those materials comprise poly(vinyl alcohol) [69], poly(ethylene glycol) (PEG) [70] or collagen, hyaluronic acid [71] (Figure 2, [72]), alginate [73], 


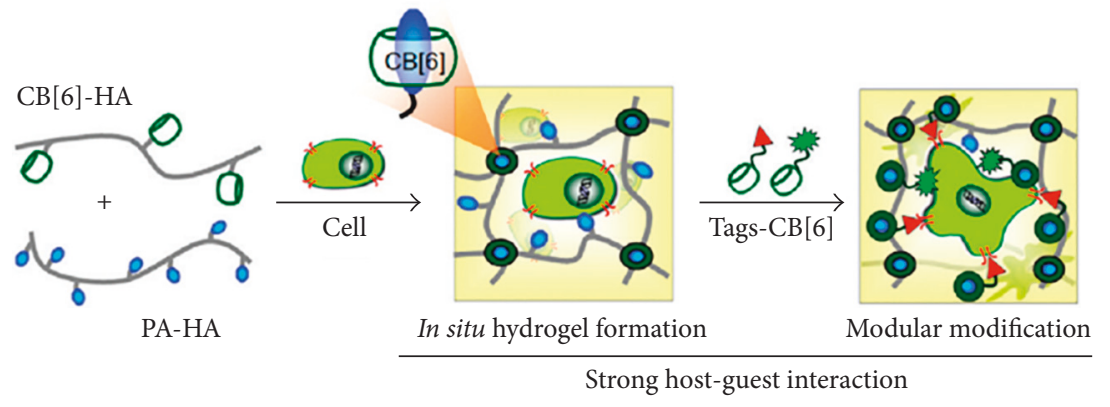

(a)

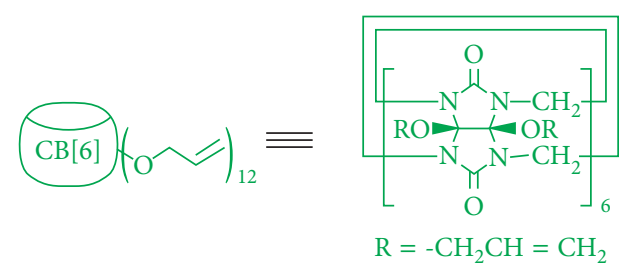

(b)

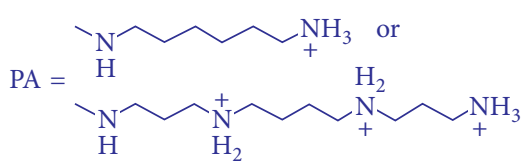

(c)

Figure 2: The functional hydrogel containing hyaluronic acid. Adapted with permission from (p. 2961) [72], copyright 2012 ACS Publications.

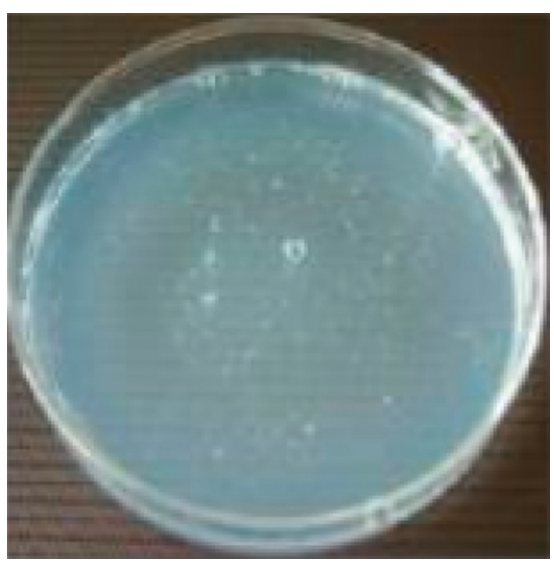

(a)

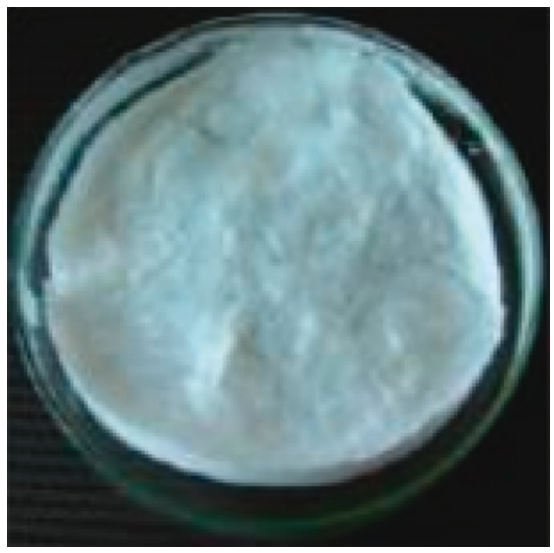

(d)

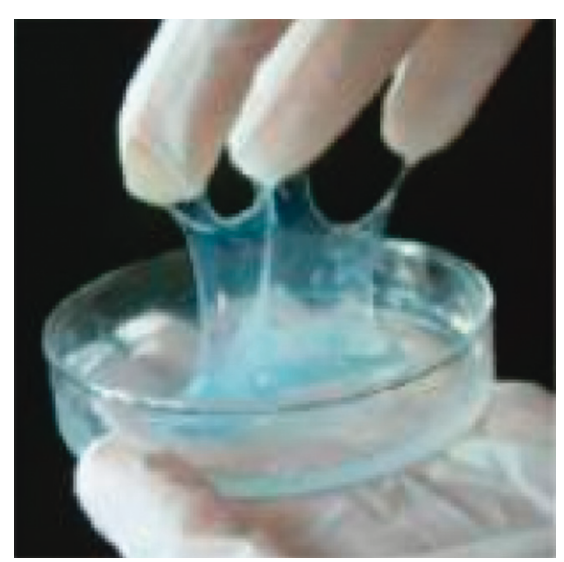

(b)

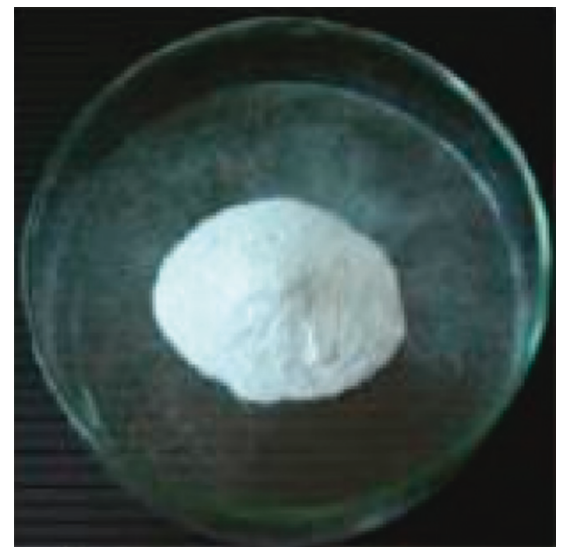

(e)

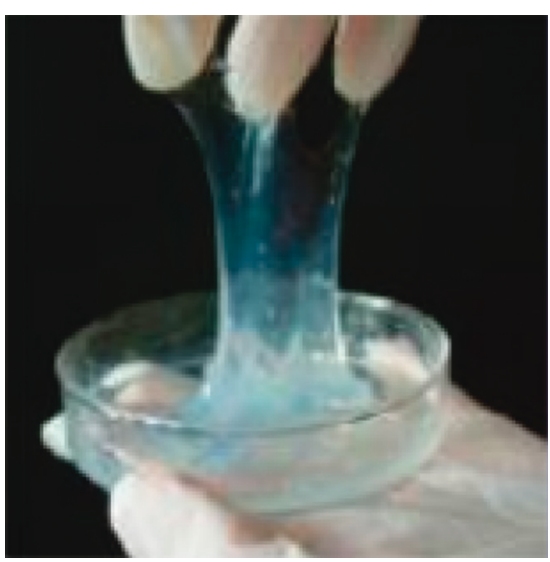

(c)

FIgURE 3: The fabrication of $\gamma$-PGA/gelatin hydrogel. Adapted with permission from (p. 692) [78], copyright 2014 ACS Publications.

chondroitin sulfate [74], heparin [75], gelatin [76, 77] (Figure 3, [78]), and chitosan [79]. Injectable polymeric hydrogel enables to be prepared via both chemical and physical ways. Chemical hydrogel is typically generated by covalent conjugation under crosslinking process, while injectable physical hydrogel is naturally made by feeble 
secondary bonding of force [80]. Additionally, the binding peptides noncovalently attach on chondroitin sulfate and hyaluronic acid to biomimic the natural instincts of extracellular matrix and potentially enhance performance. [81, 82]. These water-soluble, vastly charged GAGs have been acknowledged for assistance in moisturizing tissue and donated to the mechanical property of enhancement for the natural articular cartilage tissue [83]. A detailed discussion regarding the classification, advantages, disadvantages, and future outlooks of these applied hydrogels is provided below.

\section{Crosslinking Approaches for Fabricating Hydrogel}

\subsection{Crosslinking Approaches Using Chemically Modified} Process. Hydrophilic polymers usually have functional groups (mainly hydroxyl, carboxyl, and amine) that may be utilized for the fabrication of hydrogels. Covalent conjugations between polymeric chains may be created by chemical modification of functional groups with affinity for one another, such as in a carboxyl acid-amine or a hydroxyl $/ \mathrm{NH}_{2}$-isocyanate interaction, or by Schiff base generation.

Crosslink in hydrogels may also be achieved by other methods such as condensation, crosslinking using an additional reagent, and linkage by irradiation or by using protease.

2.2. Crosslinking Approaches Using a Crystallization Process. Poly(vinyl alcohol) (PVA) is one kind of hydrophilic polymeric materials that has the feature of adhesion. When the liquid aqueous phase of PVA is kept at room temperature, they eventually transform into a gel without the requisite mechanical properties. Once the aqueous polymeric materials undergoes lyophilization, a robust and elastic hydrogel forms [84]. This feature of the gum is influenced by the PVA molecular weight, concentration, environmental temperature, and time of exposure to the lyophilization process. The development of the gel is attributed to the generation of crystallized PVA that serves as space of a physically crosslinking procedure within the complex. These gels obtained via the applied circumstances can be stable at least up to half a year at body temperature [85].

Hydrogels obtained from physical crosslinking are usually either graft copolymers or multiblock copolymers. The former may be formed from a hydrophilic polymer backbone, such as a natural polysaccharide, to which water-insoluble units or water-insoluble chains containing hydrophilic sections are bonded. Crosslinking may also be achieved by the contribution of hydrogen bonding through van der Waals forces [86], dispersion polymerization [87], and attachment functional groups by photochemical reaction [88]. It may also be achieved by enzymatically crosslinking processes for peptides [89], which involves the usage of a cross-linking reagent that is usually seriously cytotoxic and raises issues about the dependability of the prepared gel. To address these issues, hydrogels fabricated by physical crosslinking, which may be prepared by the use of some crosslinking means, for example, van der Waals interactions, crystallized process, ionic interactions, water-insoluble interactions, or peptide molecular interactions with $\mathrm{pH}$-responsive property [90], are now discussed.

As a consequence of the swollen property of hydrogel materials, they have become of interest to investigators of the vital characteristics of swollen polymers in bulk, and they have been extensively applied in other scientific fields. Other applications include their use as a novel material for disposable contacts and protein/peptide purification, a matrix for cell incubation, an artificial filler, a drug carrier for the sustained release of medicine and peptide drugs, a substance nanocarrier for nutrients, and an agent in chemical or enhanced waste recovery.

On the basis of the reactivity of the functional residuals, the fabricated hydrogels would be categorized as ion or neutral; thus, neutral hydrogels possess a dynamic role in inflammation as a result of hydrophilic-polymer physical mixing. Such mixing is caused by the net Gibbs free energy, and the polymeric property of these substances is for clinical use [85]. The intricate features of the networked filaments include their crystallizations, structures of the hydrogen bonds, ultrastructures, and colloid aggregation [91].

\subsection{Crosslinking Way Using Free-Radical-Interaction} Polymerization. The swelling features of a hydrogel material may be adjusted using the desired amount of crosslinker. Triggerable materials can be acquired by the use of a crosslinker with the desired characteristics. One way of achieving the crosslinking process is through radical polymerized process, in which crosslinking hydrogels by chemical modification may also be achieved by free radical polymerization of hydrophilic polymeric materials with functional groups. Various hydrophilic polymers (natural, semiartificial, and synthetic) have been studied for the development of hydrogels through this method.

2.4. Crosslinking Approaches Using Ionic Polymerization. Alginate, a natural polymer, is a biopolymer that may be crosslinked by ionic polymerization. Alginate is one kind of polysaccharides that contains negatively charged glucuronic and mannuronic acid moieties and can undergo conjugation upon addition of calcium ions. This crosslinking process is performed at a room temperature and at neutral $\mathrm{pH}$. The natural polymers can used as an extracellular matrix for embedding of living cells [68] and can be used as a drug carrier system to controllably release medicine [92]. It should also be noted that these hydrogels enable to be unstabilized by using the removal of the calcium ions from the hydrogel using a chelator. The release of a drug from a designed alginate microcarrier system can be controlled by coating the particles with positively charged polymers such as chitosan/chitin-based materials [93]. Gel microbeads are formulated by mixing an aqueous polychloro phenoxy phenol (PCPP) polymer in a water phase of $\mathrm{Ca}^{2+}$ ions.

\section{Classification of Hydrogel}

3.1. Homo- (Single-) Based Hydrogel Materials. Polymeric networks based on a single type of monomer are referred to as homo-based polymers. This is the fundamental structural 
element for any polymeric network [94]. A crosslinked structure defined by the polymerization procedure or the property of the monomer used is observed in homogeneous polymers. For example, polyethyleneglycol- (PEG-) established hydrogel materials are sensitive to an environmental stimulant; thus; these hydrogels have been extensively applied in controlled release of model drugs. As chemically crosslinked PEG hydrogels may act as functional artificial scaffolding for protein drug encapsulation and useful tissue repair, they are candidates for use in this area. This is a biomaterial with potential use in the sustained release of medicine, peptide drugs, growth factors, and living cells [95].

3.2. Copolymeric-Based Hydrogel Materials. Natural hydrogels constituted of dual kinds of monomers of which more than one is water soluble are referred to as copolymeric hydrogels. An example of this is the novel triblock polycaprolactone polyethylene glycol copolymer (PECE) polymeric hydrogel matrix, which was designed for medicine carrier systems [96]. The ring-opening polymerization of co-caprolactone was achieved using the synthetic mechanisms. mPEG has been applied as the starting agent; stannous ions were used to be an activator of another chemical compound of hexamethylene diisocyanate was used for coupling the reagent in this triblock polymer modification. Such a multipolymeric block enables the production of a hydrogel in living tissue.

3.3. Thermosensitive Hydrogel Materials. Hydrogel materials that are capable of swelling and shrinking upon thermal exposure of bulk solution of the hydrogel are classified as thermoresponsive. The deswelling and swelling properties of these hydrogels are mainly decided by the environmental temperature [97]. Thermally sensitive hydrogels should be defined as negative or positive thermosensitive carrier systems [98].

The upper critical solution temperature (UCST) is noted as a property of positive thermal sensitive hydrogels [99]. This property indicates that once the bulk temperature is lower than the UCST, the hydrogel contracts and subsequently squeezes out the solvents or interstitial fluids from within the hydrogel matrix (a process also known as dehydration). Once the bulk temperatures return above the UCST, swelling behavior occurs. As described previously, this type of hydrogel reverts to its previous state once it is in a negative temperature environment. Because of the generation of the intricate structural interactions of the hydrogen bonds, positive temperature hydrogels shrink at lower environmental temperatures. As a consequence of loose hydrogen $(\mathrm{H})$ bonding, molecular structure of the hydrogel disintegrates at high temperature. Additionally, this gel tends to swell to maximum and expands suddenly upon reaching the UCST. Many polymers and their copolymers possess such behavior, for instance, the stochastic copolymeric gel structure, ABAtype triblock copolymer [100].

It has been suggested that temperature-responsive hydrogels that form through physical crosslinking experience a solution-gelation phase transformation rather than a capacity alteration at critical bulk solution temperature, as has been reported upon previously [101]. Polysaccharide-modified polymeric materials such as $\mathrm{N}$-isopropylacrylamide, methylcellulose, and hydroxypropyl methylcellulose are temperatureresponsive hydrogels that have been widely examined [102-105]. The most well-known thermally sensitive polymeric material, poly(N-isopropylacrylamide) or named poly(PNIPAAm), shows a narrow transitional phase at a bulk aqueous temperature of $34.3^{\circ} \mathrm{C}$, which is close to body temperature for use in biological applications. The lower critical solution temperature (LCST) of poly(PNIPAAm) can therefore be adjusted by performing copolymerization conjugation with other reactive monomers [106]. Through the addition of hydrophilic monomers, the LCST of synthesized hydrogel can be increased. The LCST of this substance also decreases upon combination with water-insoluble monomers. It is also known that the substitution of hydrophobic or hydrophilic monomers may not result in any substantial alteration of the LCST.

In contrast, another type of hydrogel has the LCST as the critical parameter, which implies that this hydrogel shrivels once the bulk temperature exceeds the LCST, swelling or expanding at a temperature under the LCST. For negative temperature-sensitive hydrogels, the LCST is the most crucial parameter that can be transformed through distinct methods, for example, by blending a tiny concentration of ionic copolymeric materials into the test gel materials or by exchanging dispersed ingredient. Generally, the polymeric LCST is shifted to lower temperatures if there is a greater amount of water-insoluble components in the system, as this shifts the ratio of water-soluble to water-insoluble components [107]. These hydrogels develop in two segments: the first is the water-soluble section, such as hydrophilic functional groups-, and the second is the water-insoluble section, such as $-\mathrm{R}-$ $[108,109]$. The fluid or aqueous medium interacts with the water-soluble region by generating hydrogen bonds at temperatures below the LCST. The swelling and dissolution properties of the hydrogel are enhanced by the generated hydrogen bonds. The hydrophobic interactions with the waterinsoluble region are stronger once the temperature approaches or surpasses the LCST, when the region composed of hydrogen bonds simultaneously becomes weaker. Because of the interpolymer-chain elongation, the shrinking of the hydrogel is inevitable [110], resulting in extrusion of the interfluid via a dehydration process. An example of this type of hydrogel is polyvinylpyrrolidone (PVP)/PNIPAAM, which is applied in a controlled drug-release system.

Some IPN-based hydrogels display positive thermosensitivity a behavior in which they contract in some conditions such as low temperature and would be swollen in high temperature. As noted in the literature [110], polyacrylamide, $\mathrm{P}(\mathrm{AAm}-\mathrm{co}-\mathrm{BMA})$, and poly(acrylic acid) are thermosensitive hydrogel materials. Adding the more amount of BMA raises the observed transitional temperature of the middle polymer. The stepwise temperature changes are reversible in terms of the swelling property of the hydrogels. For example, reversibly changed properties in a rate of ketoprofen release from the monolithic device have been studied. Copolymeric hydrogels that act as negative-temperatureresponsive hydrogels have been discussed previously [111, 112]. The active substance has been noted to be released at a sustained rate mediated by the LCST [113]. The reduction of the transitional temperature upon the addition of a crosslinker was 
examined, and the most prominent swelling behavior was observed at temperatures greater than the transitional temperature for both types of copolymeric materials. Since the test gel material was shown in absent of shrink or swell because of complementary hydrophobic-hydrophilic interactions, the model drug is released from the hydrogel at a steady rate.

Positive- and negative-temperature sensitive hydrogels possess similar structural compositions. The type of bonds they possess is the main difference between these two kinds of thermally responsive hydrogels. The crosslinking process between polymeric chains is achieved through noncovalent bonding. Rather than form a transitional state of swellingshrinking, these types of gels undergo solution-gelation phase transitions.

Instead of a solution-gelation phase transitional state, the thermal response of hydrogels with chemically crosslinking components undergoes volume alterations. Certainly, hydrophobicity associated with molecular interactions or van der Waals force related to hydrogen bonds acts as a key factor in a swift volumetric alteration of the given hydrogel materials as they approach a critical solution temperature (CST). At the situation of swelling, $\mathrm{H}_{2} \mathrm{O}$-molecular $\mathrm{H}$-bond interacted with the polar group of a polymer chain inside the hydrogel and coordinated with the surrounding hydrophobic moiety, such as cold water. When the CST is reached, the hydrogen bonds at the interface between polymer and water break, which in turn forces the rapid dehydration of the gel system. As the water is discharged, the entropy substantially changes because of shrinkage of the polymeric structure [114]. An example of such a polymer is poly (ethylene oxide) and poly(p-phenylene oxide) derivative (PEO-PPO-PEO), which is based on a thermally reversible hydrogel. It is vital that these thermally reversible hydrogels for clinical use possess biodegradability. In order to study the biodegradability, the polymeric material PEO-PPO-PEO, which contains a PPO segment, is commonly substituted with PLA. The suitable molecular weight and suitable structure combination caused by a hydrogel structure with changeable LCST points at either body or room temperature.

Hydrogels that possess thermal reversibility characterize the utmost imperative category of hydrogel materials. The water phase of these materials is subject to the gelation transitional state in solution in response to real stimuli. The hydrophobic region of the polymeric structure can be crosslinked in an aqueous state through a reversible thermal gelation process in which the hydrophobic derivative is integrated into the hydrophilic domain by attachment or copolymerization, and the surfactant-like substances are water soluble at relatively low temperatures. The solvent's entropy is therefore increased besides their hydrophobicity region is aggregated in order to reduce its surface area once the temperature is increased. The gelation process via thermal effect is decided by the hydrophobic and hydrophilic interactions, polymer concentration, and the chemical intrinsic quality of the polymer. The solution-gelation process related to the reversible transitional property has been discussed previously [115]. The most generally used thermally reversible hydrogels have been adopted by the Environmental Protection Agency (EPA) and Food and Drug
Administration (FDA) for applications in agronomic goods, food ingredients, and medicinal additives.

The crosslinking substances, as well as nonbiocompatibie and nonbiodegradabile monomers, that are used to fabricate thermally responsive hydrogels based on PNIPAAM and its derivatives represent the main limitations for these hydrogels. They result in immune response, as well as toxic, teratogenic, and carcinogenic effects. Clinical data are still unclear as to whether the metabolism of PNIPAAM and acrylamide constructed polymeric materials could trigger the activation of platelets once contacting with systemic blood; detailed toxicity results are required before further application. In addition, it is needed to study the valuable features of thermal hydrogels in terms of the improvement and development of fabrication of new biocompatible and biodegradable thermally responsive hydrogels.

3.4. pH-Sensitive Hydrogels. Hydrogels that are responsive to outside stimuli undergo switches in their developmental activities, linkage construction, mechanical properties, and solubility. These systems are therefore termed environmentally responsive, intelligent hydrogel systems [116, 117]. Nonchemically induced changes are considered to be those caused by thermal effects, electric force, light, magnetic change, mechanical force, and the strength of numerous energy sources, in which transfer molecular interactions play an important role. Chemical stimuli include chemical reagents, ionic strength, and $\mathrm{pH}$ value, which influence the interfaces between the solvents, polymeric molecules, and within the 3D structure of the polymer molecule.

Another type of hydrogel, known as a multisensitive hydrogel, is made by consolidation of the two stimulussensitive characteristics of the hydrogel model. Polyacrylic acid-co-polyvinyl sulfonic acid has been considered as this case [118]. The biological response takes in a reaction with protease, ligands bonding, antibodies, or some active substances $[116,117]$. Therefore, these stimuli make this type of hydrogel interesting for biomedical, therapeutic, and living applications [101].

Polymer hydrogel materials in the presence of ionic side residuals which could receive and provide $\mathrm{H}^{+}$in reply to an alteration in the $\mathrm{pH}$ value were studied by this research group [119]. At a given $\mathrm{pH}$ value, the amount of ions present in a $\mathrm{pH}$-sensitive polymeric hydrogel, denoted as $\mathrm{pK}$ or PI, changes dramatically relative to another $\mathrm{pH}$ value. A swift capacity transition in opposition to the repulsively interacted force among the ionic residuals results in a quick transformation in the final charged characters of the ionic functional residuals, which generates large permeable swelling driving force. A common example is two classes of $\mathrm{pH}$-sensitive hydrogels: one with a negative charge and one with a positive charge. Negatively charged hydrogels have side groups such as sulfonic or carboxylic acid, in which the deprotonated state exists when the test $\mathrm{pH}$ value is beyond the isoelectric point, which indicates the ionizations of the side groups. Here, the swelling behavior of the polymeric solution occurs [120-122]. Alternatively, positively charged hydrogels include functional groups such as those that are amine bound, in which 
the ionic state exists below the $\mathrm{pK}_{\mathrm{b}}$, resulting in swelling behavior due to the enhanced electric repulsive force. The extent of the swelling behavior of the soluble hydrogels is subject to many factors, as suggested by previous research $[90,123]$. The characteristics of the polymeric substance, for instance, ionic strength, hydrophilicity or hydrophobicity, dosage, isoelectric point of the functional groups, crosslinker concentration, and solubility, should be of primary concern. The states of the swelling solution such as the ionic concentration, environmental $\mathrm{pH}$, repulsive ions, and the valence of the special polymer are included in the secondary factor to be considered $[124,125]$. The capability of a novel methacrylate-based polymer with a copolymeric structure to be functioned to a pH value has been proven previously $[126,127]$ and has been applied to a designed alginate-/chitosan-mixed gel particle decorated with chitosan that was used in a given drug delivery system targeting the colon. The above investigations suggest that the degree of swelling at neutral $\mathrm{pH}$ is noticeably greater than that at lower $\mathrm{pH}(1.2)$ and thus imply the $\mathrm{pH}$ responsiveness of these hydrogels. The swelling behavior has been noted to drop because of the presence of the alginate/chitosan-mixed gel particles and by chitosan decorating due to the ionic change and the hydrogen bonding of the side groups of the polymeric moiety. As noted, chitosan has been considered as a potential biomedical material for wide use. The relative study of chitosan hydrogel was previously published (Figure 4).

A hydrogel composed of a starch-based polymer, sodium acrylate-co-acrylamide, possesses ultra-absorbent property along with $\mathrm{pH}$ sensitivity. The ibuprofen-release behavior of this hydrogel has been previously studied in a simulated intestinal and gastric pH environment [129]. The rate of swelling of this hydrogel in relation to different size of particle was studied; then it has been determined if burst release of the drug is much faster at $\mathrm{pH} 7.4$ when compared with release at lower $\mathrm{pH}$. Although a polymeric matrix with low degradability should not be a main issue when considering real-world uses of this substance, such as in oral administration, it may be a dangerous limitation when this substance is used for other purposes, such as drug-targeted release and use within a surgically implantable biochip. Thus, the development of these hydrogels should be focused toward the improvement of $\mathrm{pH}$-responsive hydrogels with biodegradability and biocompatibility and is developed from extracellular matrix (ECM) proteins, functional peptides, and positively or negatively charged polysaccharides.

3.5. Protein-/Polypeptide-Constructed Hydrogel Materials. The mentioned hydrogels are specially developed with special considerations, using the DNA stereochemistry technology to molecularly engineer recombinant and defined molecular structures for use in tissue engineering, organ transplantation, and controllable drug-release applications. Another example of these techniques makes use of the coiledcoil structure, which is found in protein-/polypeptide-based hydrogels. Coiled-coil proteins with hydrophobic amino acid parts are used as physical crosslinking agents to construct protein/polypeptide artificial hydrogels. The coiled-coil

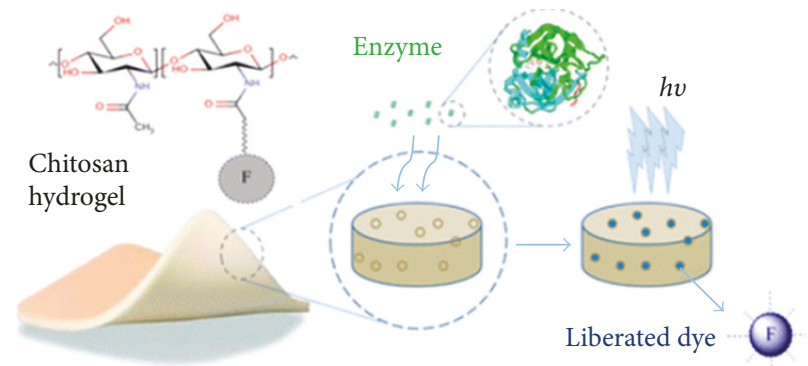

FIGURE 4: Illustration of the hydrogels composed of chitosan. Adapted with permission from [128], copyright 2014 ACS Publications.

domains of the triblock copolymers that exist at the end of the polymer and in the hydrophilic protein residues in the center of the polymer can be used to develop physically crosslinked protein-based hydrogels, and this has been studied previously [130-132]. With these hydrogels, both the $\mathrm{pH}$ and environmental temperature can affect the hydrogel in different ways according to the placement of the coiled-coil segments' amino acid structure and the hydrophilic protein domains, which can be manipulated to improve cell interactions. To fabricate the $3 \mathrm{D}$ polymeric hydrogel structure, a hydrophilic linear typical polymer such as coiled-coil protein may be used as a crosslinking agent [133].

The utilization of fluorescence correlation spectroscopy in order to estimate the protein motion rates, along with the intensity profiles on the cellular membranes and the cell junctional structure of capillary endothelial cells in living tissue, has been previously investigated [134]. When applied as protein delivery carrier systems, these hydrogels display the ability to produce a physical steric hindrance barrier in relation to the distribution of the test proteins or polypeptides. These reacted chains are also "attachable" to these polypeptides or proteins, and the feeble interaction between them additionally determines the motional behavior of the polypeptides or proteins $[134,135]$.

3.6. Blood-Sugar-Sensitive Hydrogel Materials. In a clinical study on the treatment of diabetic patients, a glucosesensitive carrier composed of a hydrogel that is designed for biomedical use should be established. Glucose-sensing hydrogel materials are candidates that would be used as a glucose monitoring system for diabetic patients [136, 137]. Researchers have found a suitable category of such material, known as "bio-smart" material, which combines the artificial molecular identification with actuation and contains poly (methyl acrylate) and (hydroxyethyl) methacrylate [138, 139]. To use functional hydrogel in diabetic study, when the glucose oxidation enzyme in the presence of oxygen transforms blood sugar to gluconic acid, the local $\mathrm{pH}$ value of the bulk medium decreases, where change rises the swelling property of positively charged hydrogels and thus discharges the insulin. In order to reduce the burst release of insulin from the carrier system and to enhance the controllable encapsulation of insulin, the oxidation enzyme for blood sugar has been covalently conjugated within the hydrogel carrier system. 
As previously investigated [140], possible molecular mechanisms resulting from blood sugar may be used as a smart sensor. The use of concanavalin A a crosslinking agent has also been investigated in order to optimize glucosesensitive hydrogels [141]. Because glucose oxidase enables the oxidization of blood sugar into gluconic acid, it is commonly used as a digestion enzyme in glucose sensing, which therefore influences the $\mathrm{pH}$ value of this carrier system and allows the use of $\mathrm{pH}$-responsive hydrogels for the controlled triggered release of insulin. Because of the ionic state, the enhanced solubility of the released insulin or other drugs may be achieved by reducing the $\mathrm{pH}$ in poly(dimethylaminoethyl methacrylate)(PDEAEM-) based hydrogels in order to improve the swelling behavior. To immobilize glucose oxidase and to use a porous membrane filter conjugated with polyanionic materials such as methacrylic acid-co-butyl methacrylate, this model of a drug carrier system should be designed in the use of a glucoseresponsive hydraulic flow controller. At physiologic $\mathrm{pH}$, the chain swells. As the $\mathrm{pH}$ drops, however, the chains are disrupted and the carboxyl groups protonated by the blood sugar may be being transformed into gluconic acid by way of the oxidant enzyme of blood sugar.

\section{Conclusion}

This review covers previously published articles from earlier in the decade that are related to polymeric hydrogels. The hydrogels are categorized in terms of the various physical and chemical features that allow them to be triggered in carrier systems in environmental, industrial, and biomedical applications (articular cartilage tissue in particular). Polymeric hydrogels formed from distinct procedures are influenced by the fabrication of the desired hydrogels and by the development of a protocol of fabrication, in which a highly sensitive material is necessary and must be defined. This review illustrates that the constitution of polymeric substances that respond to distinct stimulants such as biochemical, physical, or chemical stimulants should be recognized. Hydrogels for development that either do or do not spontaneously swell when in contact with living cells should be studied. The novel classification of such substances should be considered for future studies regarding these materials. In order to facilitate in organizing cartilage tissue engineering, hydrogels that possess biocompatibility, improved stability, mechanical strength, and biodegradability should be investigated on a nanomanufacture scale for current uses. Understanding medical needs and concurrently lessening the difficulty of hydrogel construction should therefore be the goal for future research in this field.

\section{Conflicts of Interest}

All authors declare no conflicts of interest.

\section{Authors' Contributions}

Er-Yuan Chuang and Chih-Wei Chiang contributed equally to this reviewed paper. Er-Yuan Chuang and Chih-Wei Chiang collected researched literatures and arranged the outline of the collected document; Er-Yuan Chuang, Chih-Wei Chiang, Pei-Chun Wong, and Chih-Hwa Chen discussed the content of the paper and wrote the article. All authors reviewed and commented on the entire manuscript.

\section{Acknowledgments}

This reviewed article was financially helped from a grant of Taipei Medical University (Hospital) (TMU105-AE1-B09 and TMU101-AE1-B63) and the government project of Ministry of Science and Technology (MOST) of Taiwan (MOST1052314-B-038-015-MY3 and MOST106-2314-B-038-022-MY2).

\section{References}

[1] R. Censi, A. Dubbini, and P. Matricardi, "Bioactive hydrogel scaffolds-advances in cartilage regeneration through controlled drug delivery," Current Pharmaceutical Design, vol. 21, no. 12, pp. 1545-1555, 2015.

[2] N. Eslahi, M. Abdorahim, and A. Simchi, "Smart polymeric hydrogels for cartilage tissue engineering: a review on the chemistry and biological functions," Biomacromolecules, vol. 17, no. 11, pp. 3441-3463, 2016.

[3] H. Akkiraju and A. Nohe, "Role of chondrocytes in cartilage formation, progression of osteoarthritis and cartilage regeneration," Journal of Developmental Biology, vol. 3, no. 4, pp. 177-192, 2015.

[4] C. B. Carballo, Y. Nakagawa, I. Sekiya, and S. A. Rodeo, "Basic science of articular cartilage," Clinics in Sports Medicine, vol. 36, no. 3, pp. 413-425, 2017.

[5] Y. Gao, S. Liu, J. Huang et al., "The ECM-cell interaction of cartilage extracellular matrix on chondrocytes," BioMed Research International, vol. 2014, Article ID 648459, 8 pages, 2014.

[6] J. F. Bateman, S. R. Lamande, and J. A. Ramshaw, "Collagen superfamily," in Extracellular Matrix, vol. 2, pp. 22-67, Harwood Academic Publishers, Amsterdam, Netherlands, 1996.

[7] D. R. Eyre, "Collagen: molecular diversity in the body's protein scaffold," Science, vol. 207, no. 4437, pp. 1315-1322, 1980.

[8] J. M. Clark, "The organization of collagen in cryofractured rabbit articular cartilage: a scanning electron microscopic study," Journal of Orthopaedic Research, vol. 3, no. 1, pp. 17-29, 1985.

[9] I. C. Clarke, "Articular cartilage: a review and scanning electron microscope study," Bone \& Joint Journal, vol. 53, no. 4, pp. 732-750, 1971.

[10] V. C. Mow and A. Ratcliffe, "Structure and function of articular cartilage and meniscus," Basic Orthopaedic Biomechanics, vol. 2, pp. 113-177, 1997.

[11] R. A. Stockwell, Biology of Cartilage Cells, , CUP Archive, Cambridge, UK, 1979.

[12] A. J. Sophia Fox, A. Bedi, and S. A. Rodeo, "The basic science of articular cartilage: structure, composition, and function," Sports Health: A Multidisciplinary Approach, vol. 1, no. 6, pp. 461-468, 2009.

[13] G. A. Ateshian and H. Wang, "A theoretical solution for the frictionless rolling contact of cylindrical biphasic articular cartilage layers," Journal of Biomechanics, vol. 28, no. 11, pp. 1341-1355, 1995.

[14] H. Helminen, J. Jurvelin, I. Kiviranta, K. Paukkonen, A. Saamanen, and M. Tammi, "Joint loading effects on 
articular cartilage: a historical review," in Joint Loading: Biology and Health of Articular Structures, pp. 1-46, John Wright \& Sons, Bristol, UK, 1987.

[15] T. Shen, Y. Dai, X. Li, S. Xu, Z. Gou, and C. Gao, "Regeneration of the osteochondral defect by a wollastonite and macroporous fibrin biphasic scaffold," ACS Biomaterials Science and Engineering, 2017.

[16] A Årøen, D. G. Jones, and F. H. Fu, "Arthroscopic diagnosis and treatment of cartilage injuries," Sports Medicine and Arthroscopy Review, vol. 6, no. 1, pp. 31-40, 1998.

[17] E. B. Hunziker, "Articular cartilage repair: basic science and clinical progress. A review of the current status and prospects," Osteoarthritis and Cartilage, vol. 10, no. 6, pp. 432-463, 2002.

[18] W. Widuchowski, J. Widuchowski, and T. Trzaska, "Articular cartilage defects: study of 25,124 knee arthroscopies," The Knee, vol. 14, no. 3, pp. 177-182, 2007.

[19] R. E. Outerbridge, "The etiology of chondromalacia patellae," Journal of Bone and Joint Surgery, vol. 43, pp. 752-757, 1961.

[20] T. K. Pylawka, R. W. Kang, and B. J. Cole, "Articular cartilage injuries," Injury, vol. 30, p. 3, 2006.

[21] X. Ayral, M. Dougados, V. Listrat et al., "Chondroscopy: a new method for scoring chondropathy," Seminars in Arthritis and Rheumatism, vol. 22, no. 5, pp. 289-297, 1993.

[22] M. Recht, J. Kramer, S. Marcelis et al., "Abnormalities of articular cartilage in the knee: analysis of available MR techniques," Radiology, vol. 187, no. 2, pp. 473-478, 1993.

[23] H. G. Potter, J. M. Linklater, A. A. Allen, J. A. Hannafin, and S. B. Haas, "Magnetic resonance imaging of articular cartilage in the knee. An evaluation with use of fast-spin-echo imaging," Journal of Bone and Joint Surgery, vol. 80, no. 9, pp. 1276-1284, 1998.

[24] M. P. Recht, D. W. Piraino, G. A. Paletta, J. P. Schils, and G. H. Belhobek, "Accuracy of fat-suppressed three-dimensional spoiled gradient-echo FLASH MR imaging in the detection of patellofemoral articular cartilage abnormalities," Radiology, vol. 198, no. 1, pp. 209-212, 1996.

[25] Y. Kawahara, M. Uetani, N. Nakahara et al., "Fast spin-echo MR of the articular cartilage in the osteoarthrotic knee: correlation of MR and arthroscopic findings," Acta Radiologica, vol. 39, no. 2, pp. 120-125, 1998.

[26] J. Gagliardi, E. Chung, V. Chandnani et al., "Detection and staging of chondromalacia patellae: relative efficacies of conventional MR imaging, MR arthrography, and CT arthrography," American Journal of Roentgenology, vol. 163, no. 3, pp. 629-636, 1994.

[27] D. Disler, T. McCauley, C. Kelman et al., "Fat-suppressed three-dimensional spoiled gradient-echo MR imaging of hyaline cartilage defects in the knee: comparison with standard MR imaging and arthroscopy," American Journal of Roentgenology, vol. 167, no. 1, pp. 127-132, 1996.

[28] M. Bredella, P. Tirman, C. Peterfy et al., "Accuracy of T2weighted fast spin-echo MR imaging with fat saturation in detecting cartilage defects in the knee: comparison with arthroscopy in 130 patients," American Journal of Roentgenology, vol. 172, no. 4, pp. 1073-1080, 1999.

[29] E. Hefti, W. Müller, R. Jakob, and H.-U. Stäubli, "Evaluation of knee ligament injuries with the IKDC form," Knee Surgery, Sports Traumatology, Arthroscopy, vol. 1, no. 3-4, pp. 226234, 1993.

[30] M. Ferrari, K. Louati, A. Miquel, A. Behin, O. Benveniste, and J. Sellam, "Quickly progressive amyotrophy of the thigh: an unusual cause of rapid chondrolysis of the knee," Joint Bone Spine, vol. 82, no. 3, pp. 203-205, 2015.

[31] M. Chamberlain, G. Care, and B. Harfield, "Physiotherapy in osteoarthrosis of the knees: a controlled trial of hospital versus home exercises," International Rehabilitation Medicine, vol. 4, no. 2, pp. 101-106, 1982.

[32] M. Lau, J. Lam, E. Siu, C. Fung, K. Li, and M. Lam, "Physiotherapist-designed aquatic exercise programme for community-dwelling elders with osteoarthritis of the knee: a Hong Kong pilot study," Hong Kong Medical Journal, vol. 20, no. 1, pp. 16-23, 2014.

[33] R. W. Jackson and C. Dieterichs, "The results of arthroscopic lavage and debridement of osteoarthritic knees based on the severity of degeneration," Arthroscopy, vol. 19, no. 1, pp. 13-20, 2003.

[34] N. M. Brown, C. A. Cipriano, M. Moric, S. M. Sporer, and C. J. Della Valle, "Dilute betadine lavage before closure for the prevention of acute postoperative deep periprosthetic joint infection," Journal of Arthroplasty, vol. 27, no. 1, pp. 27-30, 2012.

[35] J. R. Steadman, W. G. Rodkey, S. B. Singleton, and K. K. Briggs, "Microfracture technique for full-thickness chondral defects: technique and clinical results," Operative Techniques in Orthopaedics, vol. 7, no. 4, pp. 300-304, 1997.

[36] K. Mithoefer, R. J. Williams, R. F. Warren et al., "Chondral resurfacing of articular cartilage defects in the knee with the microfracture technique," Journal of Bone and Joint Surgery, vol. 88, pp. 294-304, 2006.

[37] K. Mithoefer, R. J. Williams, R. F. Warren et al., "The microfracture technique for the treatment of articular cartilage lesions in the knee," Journal of Bone and Joint Surgery, vol. 87, no. 9, pp. 1911-1920, 2005.

[38] T. Furukawa, D. R. Eyre, S. Koide, and M. Glimcher, "Biochemical studies on repair cartilage resurfacing experimental defects in the rabbit knee," Journal of Bone and Joint Surgery, vol. 62, no. 1, pp. 79-89, 1980.

[39] P. Kreuz, M. Steinwachs, C. Erggelet et al., "Results after microfracture of full-thickness chondral defects in different compartments in the knee," Osteoarthritis and Cartilage, vol. 14, no. 11, pp. 1119-1125, 2006.

[40] F. Shapiro, S. Koide, and M. J. Glimcher, "Cell origin and differentiation in the repair of full-thickness defects of articular cartilage," Journal of Bone and Joint Surgery, vol. 75, no. 4, pp. 532-553, 1993.

[41] G. Bentley, L. Biant, S. Vijayan, S. Macmull, J. Skinner, and R. Carrington, "Minimum ten-year results of a prospective randomised study of autologous chondrocyte implantation versus mosaicplasty for symptomatic articular cartilage lesions of the knee," Journal of Bone and Joint Surgery, vol. 94, no. 4, pp. 504-509, 2012.

[42] G. Filardo, E. Kon, F. Perdisa, C. Tetta, A. Di Martino, and M. Marcacci, "Arthroscopic mosaicplasty: long-term outcome and joint degeneration progression," The Knee, vol. 22, no. 1, pp. 36-40, 2015.

[43] L. Hangody, G. Vásárhelyi, L. R. Hangody et al., "Autologous osteochondral grafting-technique and long-term results," Injury, vol. 39, no. 1, pp. 32-39, 2008.

[44] M. Brittberg, A. Lindahl, A. Nilsson, C. Ohlsson, O. Isaksson, and L. Peterson, "Treatment of deep cartilage defects in the knee with autologous chondrocyte transplantation," New England Journal of Medicine, vol. 331, no. 14, pp. 889-895, 1994.

[45] C. Erggelet, M. Sittinger, and A. Lahm, "The arthroscopic implantation of autologous chondrocytes for the treatment of full-thickness cartilage defects of the knee joint," Arthroscopy, vol. 19, no. 1, pp. 108-110, 2003. 
[46] J. R. Foran, N. M. Brown, C. J. Della Valle, R. A. Berger, and J. O. Galante, "Long-term survivorship and failure modes of unicompartmental knee arthroplasty," Clinical Orthopaedics and Related Research ${ }^{\circledast}$, vol. 471, no. 1, pp. 102-108, 2013.

[47] R. Steele, S. Hutabarat, R. Evans, C. Ackroyd, and J. Newman, "Survivorship of the St. Georg Sled medial unicompartmental knee replacement beyond ten years," Bone and Joint Journal, vol. 88, no. 9, pp. 1164-1168, 2006.

[48] S. Bhumiratana, R. E. Eton, S. R. Oungoulian, L. Q. Wan, G. A. Ateshian, and G. Vunjak-Novakovic, "Large, stratified, and mechanically functional human cartilage grown in vitro by mesenchymal condensation," Proceedings of the National Academy of Sciences, vol. 111, no. 19, pp. 6940-6945, 2014.

[49] T. A. Ahmed and M. T. Hincke, "Strategies for articular cartilage lesion repair and functional restoration," Tissue Engineering Part B: Reviews, vol. 16, no. 3, pp. 305-329, 2010.

[50] M. B. Goldring, "Update on the biology of the chondrocyte and new approaches to treating cartilage diseases," Best Practice and Research Clinical Rheumatology, vol. 20, no. 5, pp. 1003-1025, 2006.

[51] M. Brittberg, "Autologous chondrocyte implantationtechnique and long-term follow-up," Injury, vol. 39, no. 1, pp. 40-49, 2008.

[52] L. Peterson, T. Minas, M. Brittberg, and A. Lindahl, "Treatment of osteochondritis dissecans of the knee with autologous chondrocyte transplantation," Journal of Bone and Joint Surgery, vol. 85, no. 2, pp. 17-24, 2003.

[53] S. R. Frenkel and P. E. Di Cesare, "Scaffolds for articular cartilage repair," Annals of Biomedical Engineering, vol. 32, no. 1, pp. 26-34, 2004.

[54] L. Lu, X. Zhu, R. G. Valenzuela, B. L. Currier, and M. J. Yaszemski, "Biodegradable polymer scaffolds for cartilage tissue engineering," Clinical Orthopaedics and Related Research, vol. 391, pp. S251-S270, 2001.

[55] W. J. Li and R. S. Tuan, "Polymeric scaffolds for cartilage tissue engineering," Macromolecular Symposia, vol. 227, no. 1, pp. 65-76, 2005.

[56] J. Melrose, C. Chuang, and J. Whitelock, "Tissue engineering of cartilages using biomatrices," Journal of Chemical Technology and Biotechnology, vol. 83, no. 4, pp. 444-463, 2008.

[57] N. D. Broom and A. Oloyede, "The importance of physicochemical swelling in cartilage illustrated with a model hydrogel system," Biomaterials, vol. 19, no. 13, pp. 1179-1188, 1998.

[58] E. Mathiowitz, Encyclopedia of Controlled Drug Delivery, Wiley-Interscience, New York, NY, USA, 1999.

[59] O. Wichterle and D. Lim, "Hydrophilic gels for biological use," Nature, vol. 185, no. 4706, pp. 117-118, 1960.

[60] N. A. Peppas, J. Z. Hilt, A. Khademhosseini, and R. Langer, "Hydrogels in biology and medicine: from molecular principles to bionanotechnology," Advanced Materials, vol. 18, no. 11, pp. 1345-1360, 2006.

[61] M. Kobayashi and M. Oka, "Characterization of a polyvinyl alcohol-hydrogel artificial articular cartilage prepared by injection molding," Journal of Biomaterials Science, Polymer Edition, vol. 15, no. 6, pp. 741-751, 2004.

[62] J. A. Stammen, S. Williams, D. N. Ku, and R. E. Guldberg, "Mechanical properties of a novel PVA hydrogel in shear and unconfined compression," Biomaterials, vol. 22, no. 8, pp. 799-806, 2001.

[63] M. C. Cushing and K. S. Anseth, "Hydrogel cell cultures," Science, vol. 316, no. 5828, pp. 1133-1134, 2007.

[64] P. D. Benya and J. D. Shaffer, "Dedifferentiated chondrocytes reexpress the differentiated collagen phenotype when cultured in agarose gels," Cell, vol. 30, no. 1, pp. 215-224, 1982.
[65] H. Yamaoka, H. Asato, T. Ogasawara et al., "Cartilage tissue engineering using human auricular chondrocytes embedded in different hydrogel materials," Journal of Biomedical Materials Research Part A, vol. 78A, no. 1, pp. 1-11, 2006.

[66] D. Passaretti, R. P. Silverman, W. Huang et al., "Cultured chondrocytes produce injectable tissue-engineered cartilage in hydrogel polymer," Tissue Engineering, vol. 7, no. 6, pp. 805-815, 2001.

[67] R. L. Mauck, M. A. Soltz, C. C. Wang et al., "Functional tissue engineering of articular cartilage through dynamic loading of chondrocyte-seeded agarose gels," Journal of Biomechanical Engineering, vol. 122, no. 3, pp. 252-260, 2000.

[68] M. J. Lammi, "Current perspectives on cartilage and chondrocyte mechanobiology," Biorheology, vol. 41, no. 3-4, pp. 593-596, 2004.

[69] D. A. Ossipov, S. Piskounova, and J. Hilborn, "Poly(vinyl alcohol) cross-linkers for in vivo injectable hydrogels," Macromolecules, vol. 41, no. 11, pp. 3971-3982, 2008.

[70] A. Alexander, J. Khan, S. Saraf, and S. Saraf, "Poly(ethylene glycol)-poly(lactic-co-glycolic acid) based thermosensitive injectable hydrogels for biomedical applications," Journal of Controlled Release, vol. 172, no. 3, pp. 715-729, 2013.

[71] S. M. Dorsey, J. R. McGarvey, H. Wang et al., "MRI evaluation of injectable hyaluronic acid-based hydrogel therapy to limit ventricular remodeling after myocardial infarction," Biomaterials, vol. 69, pp. 65-75, 2015.

[72] K. M. Park, J.-A. Yang, H. Jung et al., "In situ supramolecular assembly and modular modification of hyaluronic acid hydrogels for 3D cellular engineering," ACS Nano, vol. 6, no. 4, pp. 2960-2968, 2012.

[73] S. J. Bidarra, C. C. Barrias, and P. L. Granja, "Injectable alginate hydrogels for cell delivery in tissue engineering," Acta Biomaterialia, vol. 10, no. 4, pp. 1646-1662, 2014.

[74] F. Wang, Z. Li, M. Khan et al., "Injectable, rapid gelling and highly flexible hydrogel composites as growth factor and cell carriers," Acta Biomaterialia, vol. 6, no. 6, pp. 1978-1991, 2010.

[75] H. J. Sim, T. Thambi, and D. S. Lee, "Heparin-based temperature-sensitive injectable hydrogels for protein delivery," Journal of Materials Chemistry B, vol. 3, no. 45, pp. 8892-8901, 2015.

[76] Z.-S. Shen, X. Cui, R.-X. Hou, Q. Li, H.-X. Deng, and J. Fu, "Tough biodegradable chitosan-gelatin hydrogels via in situ precipitation for potential cartilage tissue engineering," $R S C$ Advances, vol. 5, no. 69, pp. 55640-55647, 2015.

[77] Y. Hong, Y. Gong, C. Gao, and J. Shen, "Collagen-coated polylactide microcarriers/chitosan hydrogel composite: injectable scaffold for cartilage regeneration," Journal of Biomedical Materials Research Part A, vol. 85A, no. 3, pp. 628-637, 2008.

[78] J. Xie, H. Zhang, X. Li, and Y. Shi, "Entrapment of methyl parathion hydrolase in cross-linked poly $(\gamma$-glutamic acid)/gelatin hydrogel," Biomacromolecules, vol. 15, no. 2, pp. 690-697, 2014.

[79] R. Jin, L. M. Teixeira, P. J. Dijkstra et al., "Injectable chitosanbased hydrogels for cartilage tissue engineering," Biomaterials, vol. 30, no. 13, pp. 2544-2551, 2009.

[80] A. A. Amini and L. S. Nair, "Injectable hydrogels for bone and cartilage repair," Biomedical Materials, vol. 7, no. 2, p. $024105,2012$.

[81] L. W. Chow, A. Armgarth, J. P. St-Pierre et al., "Peptidedirected spatial organization of biomolecules in dynamic gradient scaffolds," Advanced Healthcare Materials, vol. 3, no. 9, pp. 1381-1386, 2014.

[82] J. J. Roberts, R. M. Elder, A. J. Neumann, A. Jayaraman, and S. J. Bryant, "Interaction of hyaluronan binding peptides with 
glycosaminoglycans in poly(ethylene glycol) hydrogels," Biomacromolecules, vol. 15, no. 4, pp. 1132-1141, 2014.

[83] Q. Wang, N. Hughes, S. Cartmell, and N. Kuiper, "The composition of hydrogels for cartilage tissue engineering can influence glycosaminoglycan profile," European Cells and Materials, vol. 19, pp. 86-95, 2010.

[84] N. Annabi, K. Tsang, S. M. Mithieux et al., "Highly elastic micropatterned hydrogel for engineering functional cardiac tissue," Advanced Functional Materials, vol. 23, no. 39, pp. 4950-4959, 2013.

[85] W. Hennink and C. F. Van Nostrum, "Novel crosslinking methods to design hydrogels," Advanced Drug Delivery Reviews, vol. 64, pp. 223-236, 2012.

[86] H.-P. Cong, P. Wang, and S.-H. Yu, "Stretchable and selfhealing graphene oxide-polymer composite hydrogels: a dual-network design," Chemistry of Materials, vol. 25, no. 16, pp. 3357-3362, 2013.

[87] Y. Zhang, F. Wu, M. Li, and E. Wang, "pH switching on-off semi-IPN hydrogel based on cross-linked poly(acrylamideco-acrylic acid) and linear polyallyamine," Polymer, vol. 46, no. 18, pp. 7695-7700, 2005.

[88] B. Baroli, "Photopolymerization of biomaterials: issues and potentialities in drug delivery, tissue engineering, and cell encapsulation applications," Journal of Chemical Technology and Biotechnology, vol. 81, no. 4, pp. 491-499, 2006.

[89] Y. Garcia, R. Collighan, M. Griffin, and A. Pandit, "Assessment of cell viability in a three-dimensional enzymatically cross-linked collagen scaffold," Journal of Materials Science: Materials in Medicine, vol. 18, no. 10, pp. 1991-2001, 2007.

[90] P. Gupta, K. Vermani, and S. Garg, "Hydrogels: from controlled release to $\mathrm{pH}$-responsive drug delivery," Drug Discovery Today, vol. 7, no. 10, pp. 569-579, 2002.

[91] Z. Wang, X. Hou, Z. Mao, R. Ye, Y. Mo, and D. E. Finlow, "Synthesis and characterization of biodegradable poly(lactic acid-co-glycine) via direct melt copolymerization," Iranian Polymer Journal, vol. 17, no. 10, pp. 791-798, 2008.

[92] G. Gorrasi, V. Bugatti, and V. Vittoria, "Pectins filled with LDH-antimicrobial molecules: preparation, characterization and physical properties," Carbohydrate Polymers, vol. 89, no. 1, pp. 132-137, 2012.

[93] X. Shu and K. Zhu, "A novel approach to prepare tripolyphosphate/chitosan complex beads for controlled release drug delivery," International Journal of Pharmaceutics, vol. 201, no. 1, pp. 51-58, 2000.

[94] T. Iizawa, H. Taketa, M. Maruta, T. Ishido, T. Gotoh, and S. Sakohara, "Synthesis of porous poly(N-isopropylacrylamide) gel beads by sedimentation polymerization and their morphology," Journal of Applied Polymer Science, vol. 104, no. 2, pp. 842-850, 2007.

[95] J. Lim, A. Chouai, S.-T. Lo, W. Liu, X. Sun, and E. E. Simanek, "Design, synthesis, characterization, and biological evaluation of triazine dendrimers bearing paclitaxel using ester and ester/disulfide linkages," Bioconjugate Chemistry, vol. 20, no. 11, pp. 2154-2161, 2009.

[96] C. Gong, S. Shi, P. Dong et al., "Synthesis and characterization of PEG-PCL-PEG thermosensitive hydrogel," International Journal of Pharmaceutics, vol. 365, no. 1-2, pp. 89-99, 2009.

[97] A. Richter, "Hydrogels for actuators," in Hydrogel Sensors and Actuators, pp. 221-248, Springer-Verlag, Heidelberg, Germany, 2009.

[98] W. A. Laftah, S. Hashim, and A. N. Ibrahim, "Polymer hydrogels: a review," Polymer-Plastics Technology and Engineering, vol. 50, no. 14, pp. 1475-1486, 2011.
[99] L. Serra, J. Doménech, and N. A. Peppas, "Drug transport mechanisms and release kinetics from molecularly designed poly(acrylic acid-g-ethylene glycol) hydrogels," Biomaterials, vol. 27, no. 31, pp. 5440-5451, 2006.

[100] H. Zhang, S. Guo, S. Fu, and Y. Zhao, "A near-infrared light-responsive hybrid hydrogel based on UCST triblock copolymer and gold nanorods," Polymers, vol. 9, no. 6, pp. 238-247, 2017.

[101] N. Kashyap, N. Kumar, and M. R. Kumar, "Hydrogels for pharmaceutical and biomedical applications," Critical Reviews $^{\mathrm{TM}}$ in Therapeutic Drug Carrier Systems, vol. 22, no. 2, pp. 107-150, 2005.

[102] A. Khan, M. B. H. Othman, K. A. Razak, and H. M. Akil, "Synthesis and physicochemical investigation of chitosanPMAA-based dual-responsive hydrogels," Journal of Polymer Research, vol. 20, no. 10, p. 273, 2013.

[103] E. Ruel-Gariepy and J.-C. Leroux, "In situ-forming hydrogels-review of temperature-sensitive systems," European Journal of Pharmaceutics and Biopharmaceutics, vol. 58, no. 2, pp. 409-426, 2004.

[104] H.-F. Liang, M.-H. Hong, R.-M. Ho et al., "Novel method using a temperature-sensitive polymer (methylcellulose) to thermally gel aqueous alginate as a $\mathrm{pH}$-sensitive hydrogel," Biomacromolecules, vol. 5, no. 5, pp. 1917-1925, 2004.

[105] A. S. Hoffman, "“Intelligent" polymers in medicine and biotechnology," Macromolecular Symposia, vol. 98, no. 1, pp. 645-664, 1995.

[106] X.-Z. Zhang, D.-Q. Wu, and C.-C. Chu, "Synthesis, characterization and controlled drug release of thermosensitive IPN-PNIPAAm hydrogels," Biomaterials, vol. 25, no. 17, pp. 3793-3805, 2004.

[107] L. D. Taylor and L. D. Cerankowski, "Preparation of films exhibiting a balanced temperature dependence to permeation by aqueous solutions-a study of lower consolute behavior," Journal of Polymer Science: Polymer Chemistry Edition, vol. 13, no. 11, pp. 2551-2570, 1975.

[108] F. Ullah, M. B. H. Othman, F. Javed, Z. Ahmad, and H. M. Akil, "Classification, processing and application of hydrogels: a review," Materials Science and Engineering: C, vol. 57, pp. 414-433, 2015.

[109] R. Po, "Water-absorbent polymers: a patent survey," Journal of Macromolecular Science, Part C: Polymer Reviews, vol. 34, no. 4, pp. 607-662, 1994.

[110] Y. Qiu and K. Park, "Environment-sensitive hydrogels for drug delivery," Advanced Drug Delivery Reviews, vol. 53, no. 3, pp. 321-339, 2001.

[111] L. M. Geever, D. M. Devine, M. J. Nugent et al., "Lower critical solution temperature control and swelling behaviour of physically crosslinked thermosensitive copolymers based on N-isopropylacrylamide," European Polymer Journal, vol. 42, no. 10, pp. 2540-2548, 2006.

[112] L. Geever, C. Cooney, D. Devine, S. Devery, M. Nugent, and C. Higginbotham, "Negative temperature sensitive hydrogels in controlled drug delivery," Macromolecular symposia, vol. 266, no. 1, pp. 53-58, 2008.

[113] Y. H. Bae, T. Okano, R. Hsu, and S. W. Kim, "Thermosensitive polymers as on-off switches for drug release," Die Makromolekulare Chemie, Rapid Communications, vol. 8, no. 10, pp. 481-485, 1987.

[114] R. Yoshida, K. Uchida, Y. Kaneko, and K. Sakai, “Comb-type grafted hydrogels with rapid de-swelling response to temperature changes," Nature, vol. 374, no. 6519, pp. 240-242, 1995. 
[115] B. Jeong, S. W. Kim, and Y. H. Bae, "Thermosensitive sol-gel reversible hydrogels," Advanced Drug Delivery Reviews, vol. 64, pp. 154-162, 2012.

[116] N. Peppas, P. Bures, W. Leobandung, and H. Ichikawa, "Hydrogels in pharmaceutical formulations," European Journal of Pharmaceutics and Biopharmaceutics, vol. 50, no. 1, pp. 27-46, 2000.

[117] E. S. Gil and S. M. Hudson, "Stimuli-reponsive polymers and their bioconjugates," Progress in Polymer Science, vol. 29, no. 12, pp. 1173-1222, 2004.

[118] S. I. Kang and Y. H. Bae, "A sulfonamide based glucoseresponsive hydrogel with covalently immobilized glucose oxidase and catalase," Journal of Controlled Release, vol. 86, no. 1, pp. 115-121, 2003.

[119] A. Patel and K. Mequanint, Hydrogel Biomaterials, INTECH Open Access Publisher, 2011, https://www.intechopen.com/.

[120] E. Jabbari and S. Nozari, "Synthesis of acrylic acid hydrogel by y-irradiation cross-linking of polyacrylic acid in aqueous solution," Iranian Polymer Journal, vol. 8, no. 4, pp. 263-270, 1999.

[121] F. Jianqi and G. Lixia, "PVA/PAA thermo-crosslinking hydrogel fiber: preparation and $\mathrm{pH}$-sensitive properties in electrolyte solution," European Polymer Journal, vol. 38, no. 8, pp. 1653-1658, 2002.

[122] J. Li, X. Li, X. Ni, X. Wang, H. Li, and K. W. Leong, "Selfassembled supramolecular hydrogels formed by biodegradable PEO-PHB-PEO triblock copolymers and $\alpha$-cyclodextrin for controlled drug delivery," Biomaterials, vol. 27, no. 22, pp. 4132-4140, 2006.

[123] J. P. Baker, D. R. Stephens, H. W. Blanch, and J. M. Prausnitz, "Swelling equilibria for acrylamide-based polyampholyte hydrogels," Macromolecules, vol. 25, no. 7, pp. 1955-1958, 1992.

[124] N. V. Gupta and H. Shivakumar, "Investigation of swelling behavior and mechanical properties of a $\mathrm{pH}$-sensitive superporous hydrogel composite," Iranian Journal of Pharmaceutical Research, vol. 11, no. 2, p. 481, 2012.

[125] A. Ariffin, M. Musa, M. Othman, M. Razali, and F. Yunus, "Effects of various fillers on anionic polyacrylamide systems for treating kaolin suspensions," Colloids and Surfaces A: Physicochemical and Engineering Aspects, vol. 441, pp. 306311, 2014.

[126] F. Bossard, T. Aubry, G. Gotzamanis, and C. Tsitsilianis, "pH-Tunable rheological properties of a telechelic cationic polyelectrolyte reversible hydrogel," Soft Matter, vol. 2, no. 6, pp. 510-516, 2006.

[127] T. Dolatabadi-Farahani, E. Vasheghani-Farahani, and H. Mirzadeh, "Swelling behaviour of alginate-N, O-carboxymethyl chitosan gel beads coated by chitosan," Iranian Polymer Journal, vol. 15, no. 5, p. 405, 2006.

[128] M. M. Sadat Ebrahimi and H. Schönherr, "Enzyme-sensing chitosan hydrogels," Langmuir, vol. 30, no. 26, pp. 7842-7850, 2014.

[129] M. Sadeghi and H. Hosseinzadeh, "Synthesis of starch-poly (sodium acrylate-co-acrylamide) superabsorbent hydrogel with salt and $\mathrm{pH}$-responsiveness properties as a drug delivery system," Journal of Bioactive and Compatible Polymers, vol. 23 , no. 4 , pp. 381-404, 2008.

[130] C. Wang, R. J. Stewart, and J. KopeČek, "Hybrid hydrogels assembled from synthetic polymers and coiled-coil protein domains," Nature, vol. 397, no. 6718, pp. 417-420, 1999.

[131] J. Yang, C. Xu, C. Wang, and J. Kopeček, "Refolding hydrogels self-assembled from $\mathrm{N}$-(2-hydroxypropyl)methacrylamide graft copolymers by antiparallel coiled-coil formation," Biomacromolecules, vol. 7, no. 4, pp. 1187-1195, 2006.

[132] P. Jing, J. S. Rudra, A. B. Herr, and J. H. Collier, "Selfassembling peptide-polymer hydrogels designed from the coiled coil region of fibrin," Biomacromolecules, vol. 9, no. 9, pp. 2438-2446, 2008.

[133] J. Kopeček, "Smart and genetically engineered biomaterials and drug delivery systems," European Journal of Pharmaceutical Sciences, vol. 20, no. 1, pp. 1-16, 2003.

[134] R. V. Ulijn, N. Bibi, V. Jayawarna et al., "Bioresponsive hydrogels," Materials Today, vol. 10, no. 4, pp. 40-48, 2007.

[135] E. Turan, G. Özçetin, and T. Caykara, "Dependence of protein recognition of temperature-sensitive imprinted hydrogels on preparation temperature," Macromolecular Bioscience, vol. 9, no. 5, pp. 421-428, 2009.

[136] J. T. Suri, D. B. Cordes, F. E. Cappuccio, R. A. Wessling, and B. Singaram, "Continuous glucose sensing with a fluorescent thin-film hydrogel," Angewandte Chemie International Edition, vol. 42, no. 47, pp. 5857-5859, 2003.

[137] V. L. Alexeev, A. C. Sharma, A. V. Goponenko et al., "High ionic strength glucose-sensing photonic crystal," Analytical Chemistry, vol. 75, no. 10, pp. 2316-2323, 2003.

[138] P.-C. Chen, L.-S. Wan, B.-B. Ke, and Z.-K. Xu, "Honeycombpatterned film segregated with phenylboronic acid for glucose sensing," Langmuir, vol. 27, no. 20, pp. 12597-12605, 2011.

[139] Y. Tian, B. R. Shumway, and D. R. Meldrum, "A new cross-linkable oxygen sensor covalently bonded into poly(2-hydroxyethyl methacrylate)-co-polyacrylamide thin film for dissolved oxygen sensing," Chemistry of Materials, vol. 22, no. 6, pp. 2069-2078, 2010.

[140] J. Kopeček and J. Yang, "Peptide-directed self-assembly of hydrogels," Acta Biomaterialia, vol. 5, no. 3, pp. 805-816, 2009.

[141] A. A. Obaidat and K. Park, "Characterization of protein release through glucose-sensitive hydrogel membranes," Biomaterials, vol. 18, no. 11, pp. 801-806, 1997. 


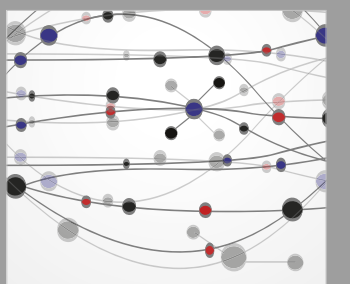

The Scientific World Journal
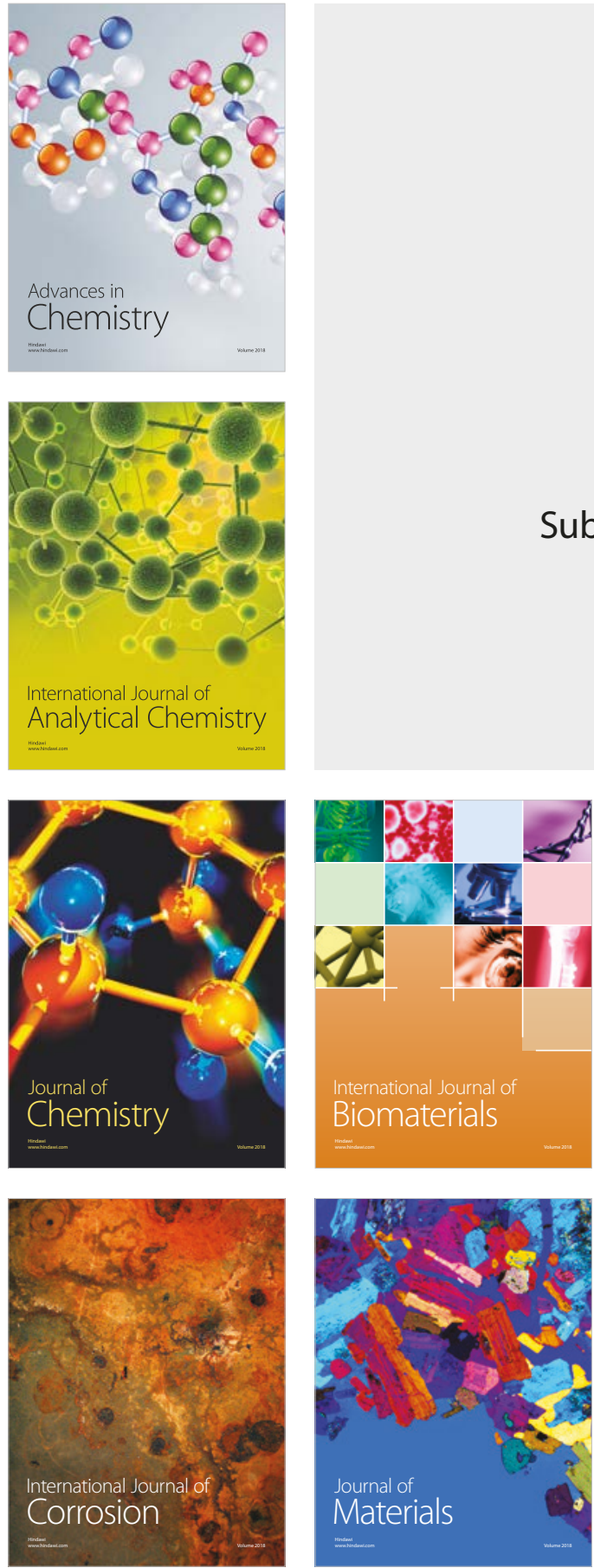

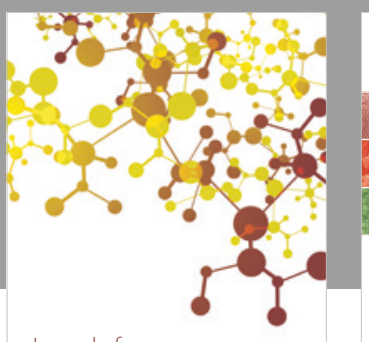

Journal of

Applied Chemistry
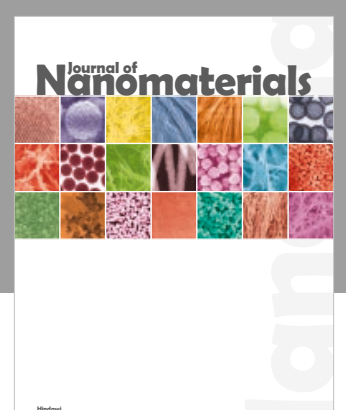

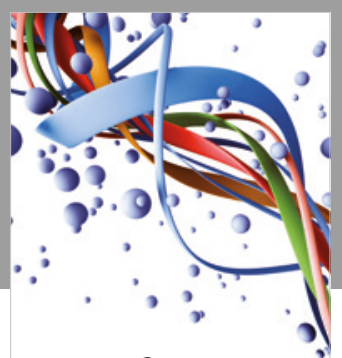

Scientifica

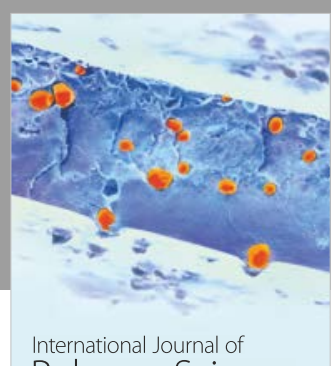

Polymer Science

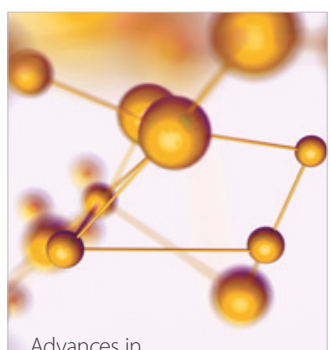

Physical Chemistry
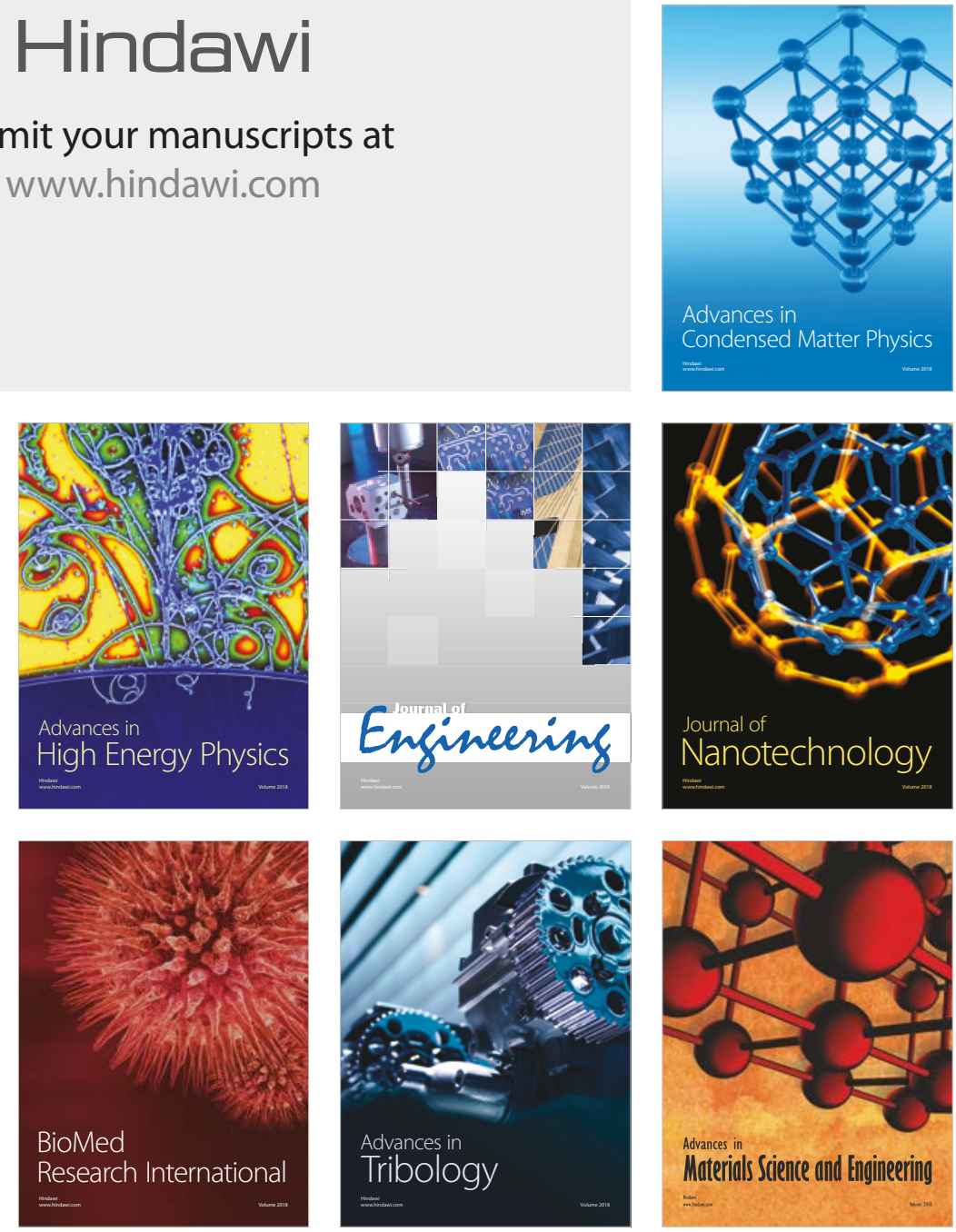